\title{
Development of Green Technology from the past to the future development: A Systematic Literature Review Paper Nornazirah Binti Nazir Ali
}

Faculty of Technology Management and Technopreneurship Universiti Teknikal Malaysia Melaka, Jalan Hang Tuah Jaya, 76100 Durian Tunggal, Melaka, Malaysia.

Murzidah binti Ahmad Murad

Faculty of Technology Management and Technopreneurship, Universiti Teknikal Malaysia Melaka, Jalan Hang Tuah Jaya, 76100 Durian Tunggal, Melaka, Malaysia. murzidah@utem.edu.my

\section{Muhammad Imran Qureshi}

Faculty of Technology Management and Technopreneurship, Universiti Teknikal Malaysia Melaka, Durian Tunggal 76100, Melaka, Malaysia. qureshi@utem.edu.my

\section{Nohman Khan}

UniKL Business School, Universiti Kuala Lumpur, Kuala Lumpur 50300, Malaysia

*Corresponding author email: nazirah_nazir@yahoo.com

\begin{abstract}
In the era of globalization today, Green technology acceptance has become a crucial sector not just for the environment, but also for humans and towards the economy. In this paper, the researcher will do the overview of Green Technology Acceptance as overall, means in many areas such as green transportation, green chemistry, green buildings, green procurements and few more. So, for this purpose the researcher choose to use the Scopus database to review on the past published studies on green technology fields. For this purpose, the Qualitative review has been done by the systematic review through the PRISMA Framework (Preferred Reporting Items for Systematic Review and Meta-Analysis). There are around 46 papers that had been selected in finals for this systematic literature review analysis. After follow the PRISMA Model to filter out the paper that suitable for this study, researcher is using the Microsoft Excels to do the descriptive analysis on year base publication, journal base, most cited by, theory utilised and subject areas. Besides that, researcher also focus on the methodology classification that had been use in the past studies. There are three main classifications which is Quantitative, Qualitative and Mixed Methods. There are around 26 paper used quantitative analysis method, 17 papers utilised qualitative method and 3 papers using mixed method. Mostly all this past study not including the latest branches of Green Technology such as green economies, green building and many more. As overall, researcher successfully using the PRISMA model to identified the suitable paper that being used in this papers.
\end{abstract}

Keywords - Green Technology; Acceptanc; Systematic Literature Review; PRISMA

\section{Introduction}

Just imagine, throughout the early days just before industrial revolution arise, people basically used the primary source, such as the sun in order to generate energy from heat. They also usually used the other source to support their daily routine, such as riding the horses as their transportation and in the same times, the wind was used to shift the sails and develop a basic generator. However, in the mid-1700s, since the first introduction of a modern steam engine by Thomas Newcomen and James Watt, people have discovered the potential of utilize the intensity of the steam power. During the 1800s, more natural resources were discovered to be valuable and capable of supplying us with a ton of ease, such as petroleum and oil used in refined the gasoline for engine combustion. Nevertheless, this convenience has triggered a lot of energy crises the whole world today owing to the rapid usage on fossil fuels such as gasoline, natural gas and oil over the past decade (Science, 2019). Moving to 1900s, there was a string of energy shortages in the Middle East, and things got worse in 1973, when the ban forced by the oil makers of Iraq on America oil producers led to a surge in the price of crude oil. By referring to this problems, United States was realizing the value of natural supplies, hence starting the initial drive to establish renewable energy which is sort of Green technology. Since this issues, people already start to make a research on the renewable energy and 
also try to find alternative resources to overcome the environmental issues. This is shows that even since 1990s, people already moving towards the Green Technology and until today it keeps develop around the whole world (Science, 2019).

If we do some research on the google regarding to this Green Technology topic, we will find number of studies or research that had been done around the world. Green Technology are not something new anymore, it's becoming as one of the important element in our life today. Now we are in the middle of 2020, we have been bombarded with various news that bring destruction to the environment. Just in few months, across Brazil, Australia and Indonesia the wildfires and also a destruction of forests and wildlife ecosystems have proven that we have arrived at a point where the damage is irreversible and cannot be undone. Mostly all around, were having some problem regarding to the devastating effects of the environment and also ecosystem. They have to face the extreme weather, floods, high temperatures, haze, air pollution, water pollution and many other issues regarding to the environment. However, through the implementation of green technology and environmentally friendly advancement, they will have the ability to hold back on this issues that had damaged the environments

Green technology has arisen as a significant movement and advancement in the 21st century as a result of the rising global environmental issues such as climate change, global warming and the lack of energy supplies. Development is bound to boost to global, sustainable and economic capabilities that will have an impact on economic policy, communities, cultural practices and the way of future lives(Show, 2010). Basically what is Green Technology? Green Technology can be define as Green technology is about man, information, formulated relationship of design theory with material production, and the results of the goods in the present and also future life (Odigure, 2016). Besides that, Green technology also the enhances of the devices, processes and goods used to conserve the natural ecosystem and energy to reduce the negative consequences of human actions (Iravani et al., 2017). In other words, green technology can be determining as a "Technology which had the potential to enhance environmental efficiency towards other technologies (Lal, 2018).

The primary purpose of green technology is to protect biodiversity, and to mitigate the negative effect of human beings. As in the early of 1990s, there has been a lot of attention on green technologies subject matter. Green technology offers significant advantages not only for biodiversity itself but also for a healthier and greener lifestyle. As now or even in the future all human beings would like to stay alive and breathing on this earth without having any ecosystem problem. These green technologies system and applications will help to guarantees the planet remains stable for the continued survival of all organisms. According to one research by (Labex Korea, 2013) its stated that there are around 38 countries had been utilised by the 15 measurements relating to the development of green solutions companies, including public legislation and practices, private financial incentives, and educational incentives. The results come out with top 10 leading countries that had been invested higher in green technology fields. The first country that leading in the green technology is Denmark. Interestingly, small countries dominate first places in the ranking of green innovation, but they are capable of big changes in a more successful environment. Denmark 's leadership is demonstrated by its potential to sustain new enterprises that develop clean technologies to make them economically and environmentally profitable. The wind power industry becomes more effective in Denmark and is estimated to generate more than half to Denmark's power consumption in the next decade by reducing emissions by $40 \%$ by 2020 . The second top country that applying green technology is Israel which at least $90 \%$ of Israel homes are currently heating the water with solar energy. Israel is the nation that spends more money in processing and treating water. The quality of this natural resource is a global benchmark. On the third ranking, Sweden became as one off the country that has centres of expertise with strategic partnerships with leading industries for accepting the environmental challenges.

\section{Branches of Green Technology}

There are few branches or section under Green Technology field. Some of the division can be seen in figure. Based on the figure above, its shows some of the branches under green technology field. Firstly, is Green Information Technology (IT). Green IT can be describe as the theory and application of designing, manufacturing, using and safely dispose of computers, servers and network devices such as projectors, devices, storage, networking and also communications set-up that have minimum or no environmental impact in an efficient manner (Lim Wei PIng, 2012). Usually green IT had been used much on organization's capability to systematically implement the 
sustainability and environmental friendly measures. Besides that, green building also one of the subtopic under Green Technology. Many of papers had been published on this topic. Green building can be defining as the practice of designing buildings and utilizing environmentally sustainable and resource efficiently techniques over the lifecycle of a construct. This includes from setting to layout, constructing, managing, servicing, restoration and everything from the selection of building supplies to the location of the building (Tahir et al., 2015) The main focus of green building is to guarantee that designs for green construction minimize the total impact on human health and the environment.



Fig1: Branches of Green Technology

In addition, Green Nanotechnology also one of the subtopics in the green technology areas. Green Nanotechnology is implementation of the combination between the green chemistry principles and green engineering to the Nano scale level. Corresponds to the use of nanotechnology to improve the sustainability of the environment from negative effects. Nanotechnology includes material processing at nanometre scale, which is one billionth of a meter (10-9). Generally, nanotechnology is being used is some sectors such as food safety, medicine, energy, transportation and many more. Next, green chemistry also one of the sub topic of green technology. Green chemistry is to preserve sustainable environmental practices and processes via the lifespan of a chemical substance (model, production, and disposal practices) (McCranie et al., 2011). This green chemistry mostly involves the fields of medicine, pharmacist and also chemical engineer because many research paper had been studied on this field also.

Moreover, green transportation also including in the green technology areas. Green transportation can improve incentives for alternate modes of travel and elimination of GHG emissions from vehicles usage. Green Transportation or known as Sustainable Transportation involves those forms of transportation that are not based on a decline of renewable resources such as fossil fuels. Such modes of transportation focus on renewable energy sources such as hybrid car or electric transportation (Krishnan et al., 2014). Lastly, one of the green technology subtopic is green energy. The renewable technologies idea interlaced with green energy. This is because green energy practices are used as a tool to support towards preserve environmental protection through the green technology sector (Markom \& Hassan, 2014). By using this green energy this bring more advantages because green energy power plants tend to have a fewer maintenance compared with conventional generators. This is because it come from natural resources, the production costs are usually lower.

As we are moving towards globalisation world, green technology field are becoming more trending nowadays. Many researchers from all over the world are doing study and research on this topic. Green technology gives more positive impact not only to environment but towards the human lifestyle also. Advantage of having this green technology is it will never be harmful to the environment and also its reduce the effects of global warming due to CO2 emissions. 


\section{Methodology}

Literature review is one of the crucial parts in the content of paper, because by having this literature review the researcher will be able to point out research gaps from previous studies. The rapid growth in the green technology field was one of the reasons for researcher to explore more about the acceptance of green technology around the world. This study will review the progress of green technology from 40 years back until todays. The main objective is to come out with systematic progress of green technology such as renewable energy, energy efficiency, zero waste and sustainability. The PRISMA Framework had been used as the method to analyse the past literature review in order to come out with systematic literature review (SLR). The PRISMA statement framework has been used to demonstrate the overview process of selection and exclusion of publications for the review of green technology acceptance (Qureshi et al., 2020). Previous study also stated that The PRISMA method lets the writer enhance the analysis of the study article. Especially in term of flow charts, which allow the readers to get an overall understanding of the process flow just by looking at the data written there and also from the direction of arrows. The PRISMA model can assist the researcher to focus on improving the review paper reporting (Khan \& Qureshi, 2020). The steps that included in this PRISMA framework including Identification, Screening, Eligibility and Included. By using this PRISMA framework, its help researcher to go smoothly among all the information gained from the Scopus database.

\section{Literature Research}

The comprehensive literature review was selected from the Scopus Database with few criteria's that had been selected for this study. First of all, researcher is using the keywords of "Green Technology" AND "Acceptance" for the search items and the results that came out is around 510 documents. Next stage, the researcher is choosing only suitable subject areas for this research which is Environmental Science, Social Science and Business, Management and Accounting. There are around 210 documents filtered out through this process. After that, the researcher filters the search item to five items which is document that had been choose as articles only, the conference paper and reviews paper are not been selected for this review paper. Language that selected for this study only limited to the English. Meanwhile for the source types, the journal was being selected to find all possible journals that are available on the Scopus database. The years for this study are not being specific as the researcher want to find out the pattern of green technology development. After selected all the criteria, the document had limited to 118 documents. Once the researcher downloads the files as Excel Microsoft, researcher limited the number of paper again by minimize the number of citation of each paper at 10 times per paper. After all, only 46 studies were remains to be used in this review paper.

\subsection{Quality Assessment}

Quality assessment one of the important part in the methodology part. In this papers, the quality assessment had been done in order to make sure that this paper was worked on the correct topic which is acceptance of green technology. Firstly, the literature review paper is on the journal source, this means review papers or conference papers were excluded during the selection process. Besides that, researcher also checked on the abstract of paper to make sure that the topic was correctly selected regarding to the keyword given. The duplicated articles also had been checked to find out if any articles were duplicate. Finally, in term citations and references also had been checked. This stage was a crucial stage as high quality assessment will take the massive amounts of interpretation data and decodes that into significant information.

\subsection{Eligibility and inclusion criteria}

All the articles that selected for this study were processed from a few criteria. First of all, the database that had been used is only Scopus with the search terms of "Green Technology" and "Acceptance". The area that selected was Social Science, Environmental Science and Business, Management and Accounting, other subject areas are excluded from this research. The language was only limited to English language for the selected papers. The years are all selected as this research to find out the implementation of green technology all around the world in past time. The sources type of data that had been chosen is journals. Overall, this paper reviews the green technology literature and also including the environmental and energy discussion also. Throughout the selection process, the selected articles were being chosen with no open access and also open access. In this review paper, researcher 
found out that the number of quantitative studies was higher compared to the qualitative studies. The citation also had been minimizing by having at least 10 times citation per articles.

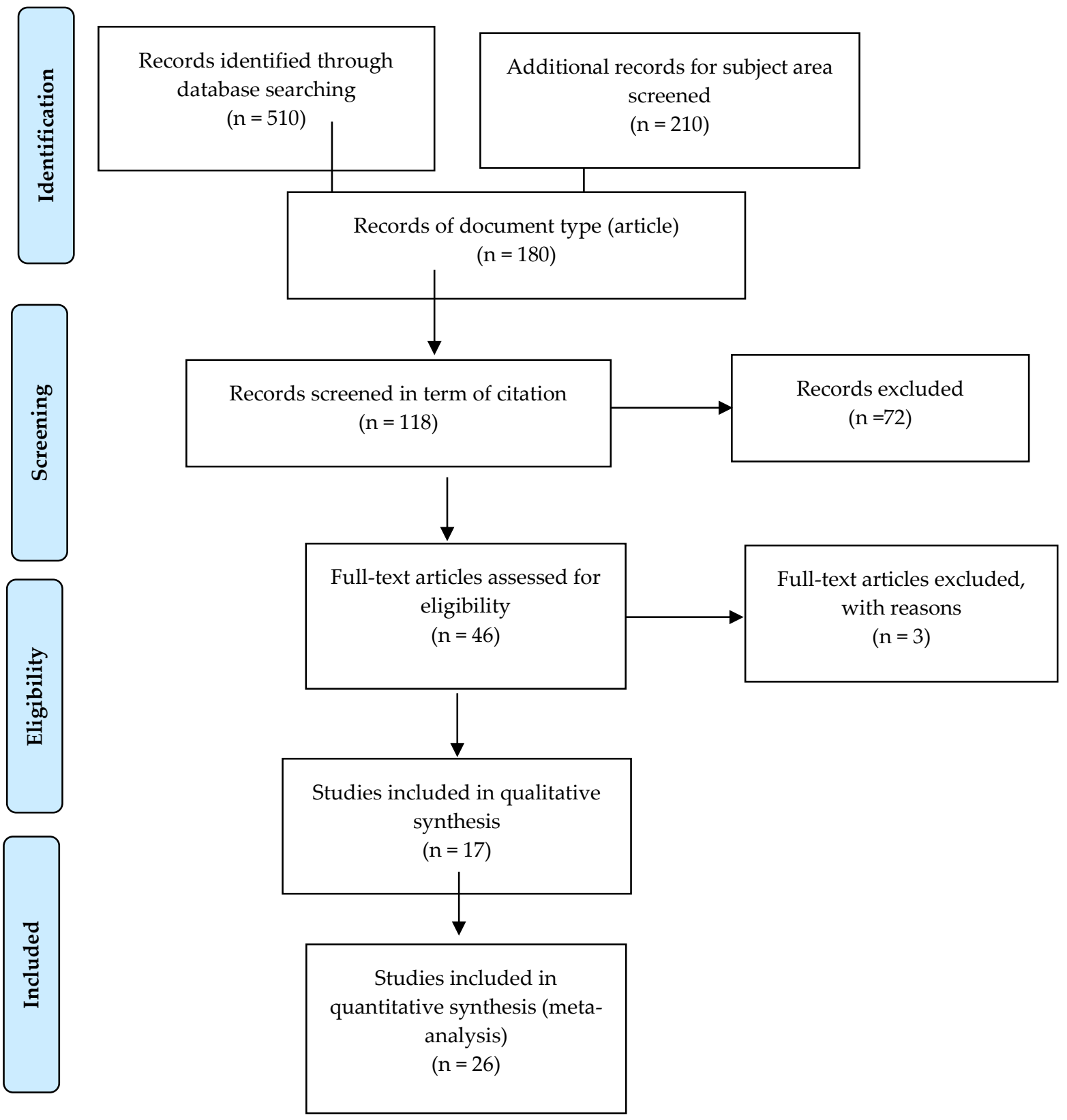

Figure 2: PRISMA 2009 Flow Diagram

\subsection{Studies included in qualitative synthesis}

After done the data extraction including the inclusion and exclusion criteria, the final results that has been process is 46 papers. Starting from the selection process by the Scopus until the researcher get one data files in Excel forms. All the data then had been filtering out to find the exact information that needed for this papers especially papers that contains the green technology acceptance topic.

\section{Results}

\subsection{Descriptive analysis}

\section{i. Year base publication}




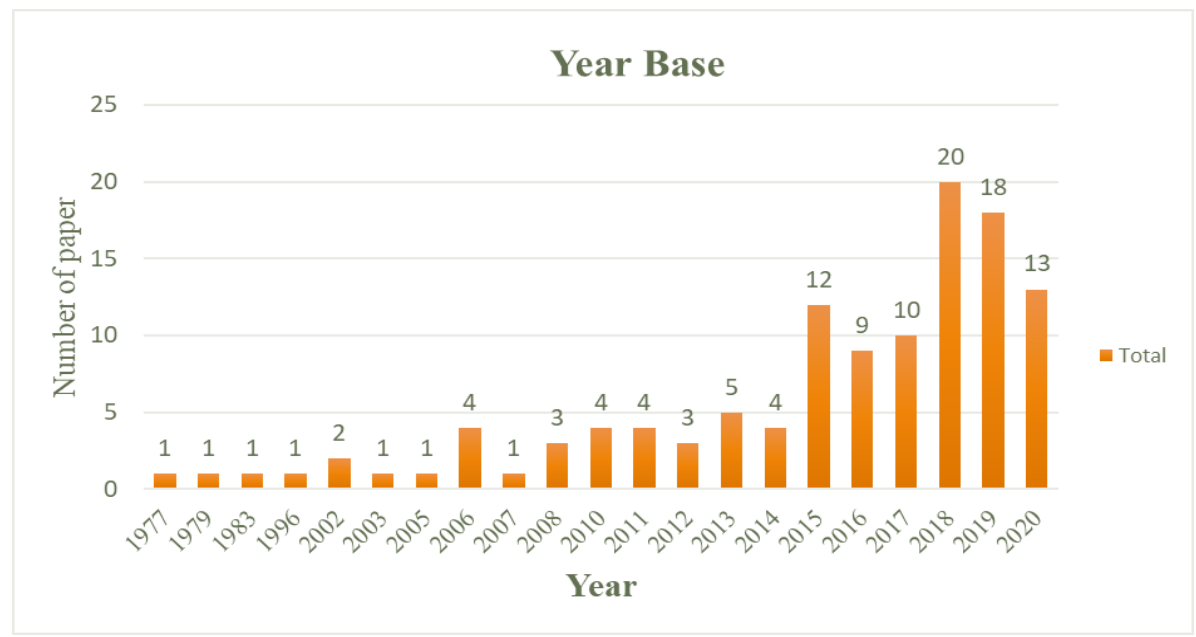

Fig 2: Year Base Publication

Based on the graph above, it showed the year-based publication on green technology acceptance fields. We can see that as early as 1977, researchers already start to do research on green technology which is around 43 years ago. The total number of the publication were gained from the Scopus database. As stated in year of 1977, 1979, 1983, 1996, 2003, 2005 and 2007 are having one publication respectively. The highest number of publication is in year of 2018, which is around 20 research papers are published on Green Technology topic. As overall, the results are showing the number of research are keep increasing years by years as in the earlier years' number of research are still limited compared to 2015 and above. This is because the green technology concept improves not only environmental sustainability but also standards of living (Ali et al., 2019). The trending of Green Technology areas is keep increasing and as in the future, many more researcher will have more interest as nowadays Green Technology already well known around the world.

\section{ii. Journal base}

Based on the Graph 4.1.2, its showed the journal base that had been selected in the selection process. Journal of Cleaner Product are the top rank in the selection process with 4 studies are published from the journal. This is one of the worldwide journal with multidisciplinary journal focused on learning and practices on Sustainable Growth, Environmental and Sustainability. Meanwhile, for the second top rank journal that published Green Technology Acceptance papers are published with 4 papers also which is under Energy policy journal which is a journal that deals with the policy ramifications of energy production and use from a cultural, social, planning and environmental point of view. Both of this journal were published a paper mostly on the green technology fields including the environmental and energy conservation. Transportation Research Journal and Energy Journal both were having three publications papers. All of this publication paper already went through a screening process and in the future, researcher hope that many journals will do publication in the environmental and energy fields because it got a warm welcome day by day. 


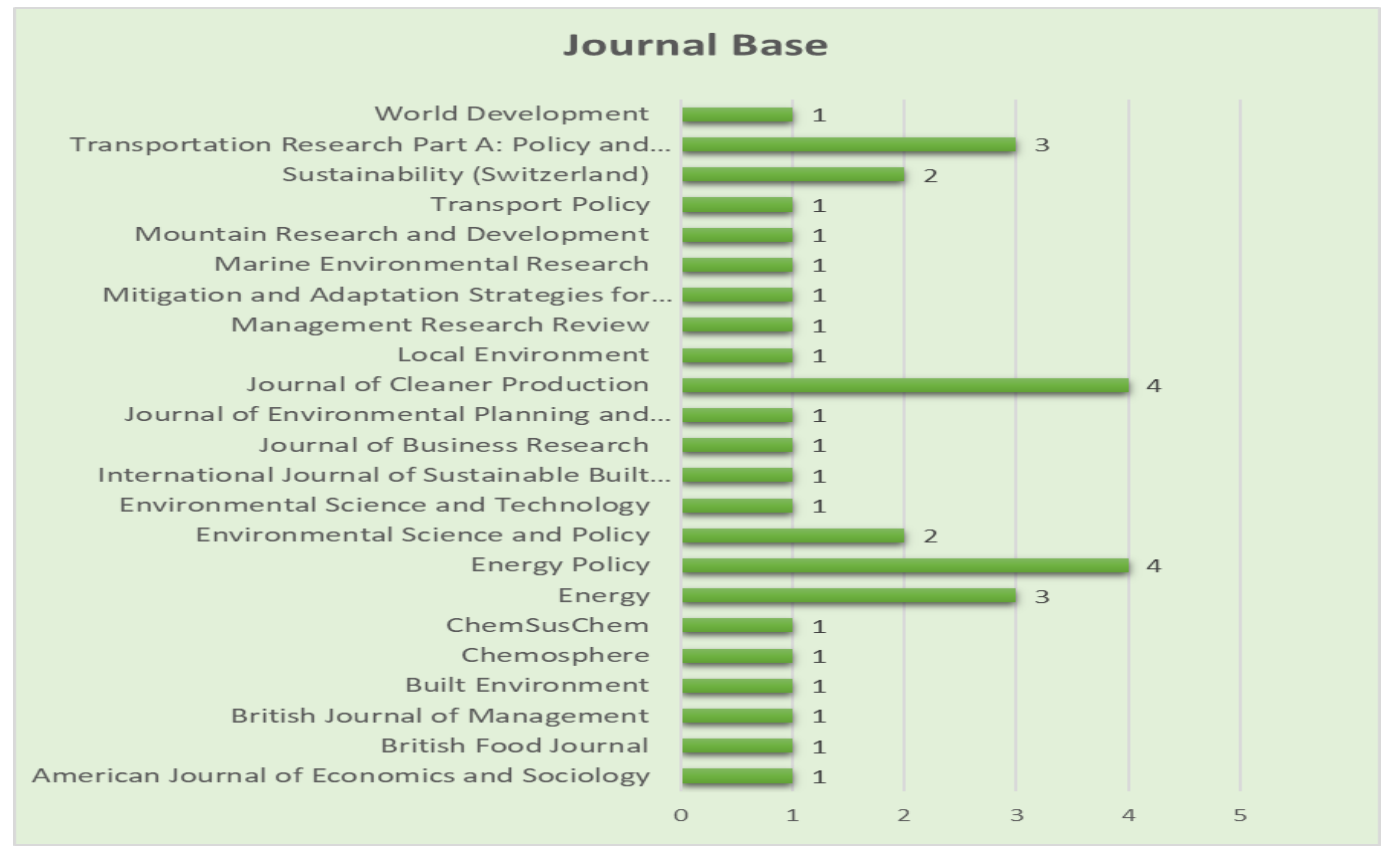

Fig 3: Journal Base

\section{iii. Most cited by}

Based on the table 4.1.3, its shown a most cited paper in this study. The highest cited paper was 'Green on green: Public perceptions of wind power in Scotland and Ireland' which is cited by 334 times since 2005. The authors in the article were Charles R. Warren, Carolyn Lumsden, Simone O'Dowd and Richard V. Birnie.

Table1: most cited by

\begin{tabular}{|c|c|c|}
\hline Years & Article & $\begin{array}{l}\text { Number of cited } \\
\text { by }\end{array}$ \\
\hline 2005 & 'Green on green': Public perceptions of wind power in Scotland and Ireland & 334 \\
\hline 2008 & Green roof valuation: A probabilistic economic analysis of environmental benefits & 155 \\
\hline 1996 & $\begin{array}{l}\text { Marketing strategies and market prospects for environmentally-friendly consumer } \\
\text { products }\end{array}$ & 153 \\
\hline 2010 & $\begin{array}{l}\text { Critical factors for implementing green supply chain management practice: An empirical } \\
\text { study of electrical and electronics industries in Taiwan }\end{array}$ & 137 \\
\hline 2011 & $\begin{array}{l}\text { Development pattern and enhancing system of automotive components } \\
\text { remanufacturing industry in China }\end{array}$ & 130 \\
\hline
\end{tabular}

This paper overview is about the evidence that supports the opinion that aesthetic preferences, both positive and negative, are the greatest single impact on human attitudes toward renewable energy projects such as wind. The second highest cited by paper is 'Green roof valuation: A probabilistic economic analysis of environmental benefits' written by Corrie Clark, Peter Adriaens, and F. Brian Talbot. This second highest paper also showed that one of the Green technology application which is green vegetated roofs has established as global acceptance that have potential to protect the environmental. Meanwhile for the third most cited by paper founded in this research with 153 citations is 'Marketing strategies and market prospects for environmentally-friendly consumer products' since 1996 until today also still being used as part of the references in the researcher paper. The fourth paper most cited by published in 2010 with title of 'Critical factors for implementing green supply chain management practice: An 
empirical study of electrical and electronics industries in Taiwan' with 137 citations. Lastly, the fifth most cited paper is written by Tongzhu Zhang, and others are cited by 130 times. All this data for the high cited papers are collected from the Scopus database and had been reviewed in this study.

\section{iv. Theory utilised}

Based on the figure above, its showed theory utilised in all review papers that had been selected in this study. Basically, the nature of study of this paper is Green Technology fields in terms of acceptance or its adoption around the world. As we can see above there are many different types of theory that had been utilised based on different type of article and their topic. The highest theory that had been utilised in this study is Technology Acceptance Model which is $29 \%$ of the study or around ten articles paper are using this theory in their research. On one of the research stated that TAM are the most widely applied compared to all other theories as TAM can figure out on how external influences are related to beliefs, perceptions, attitudes and also behaviours (Abu-dalbouh, 2013)(Fitri et al., 2017). The second theory that usually utilised in green technology acceptance field was Theory of Planned Behaviour (TPB), which is around 3 papers or $9 \%$ of the study used this theory. The theory of planned behaviour is a model of behavioural-intention from the discipline of psychology developed by Ajzen (1991) to clarify the effects on a person's "individual to adopt" behaviour (Teo et al., 2011). Other than that, there are few rarely used theory adapted in this review study. This is because some of the papers are on experimental basic which using scientific theory such as Continuous Electrode ionization (CEDI) and Biphasic System. As overall, all this theory was utilised from the paper selected based on the inclusion and exclusion criteria.

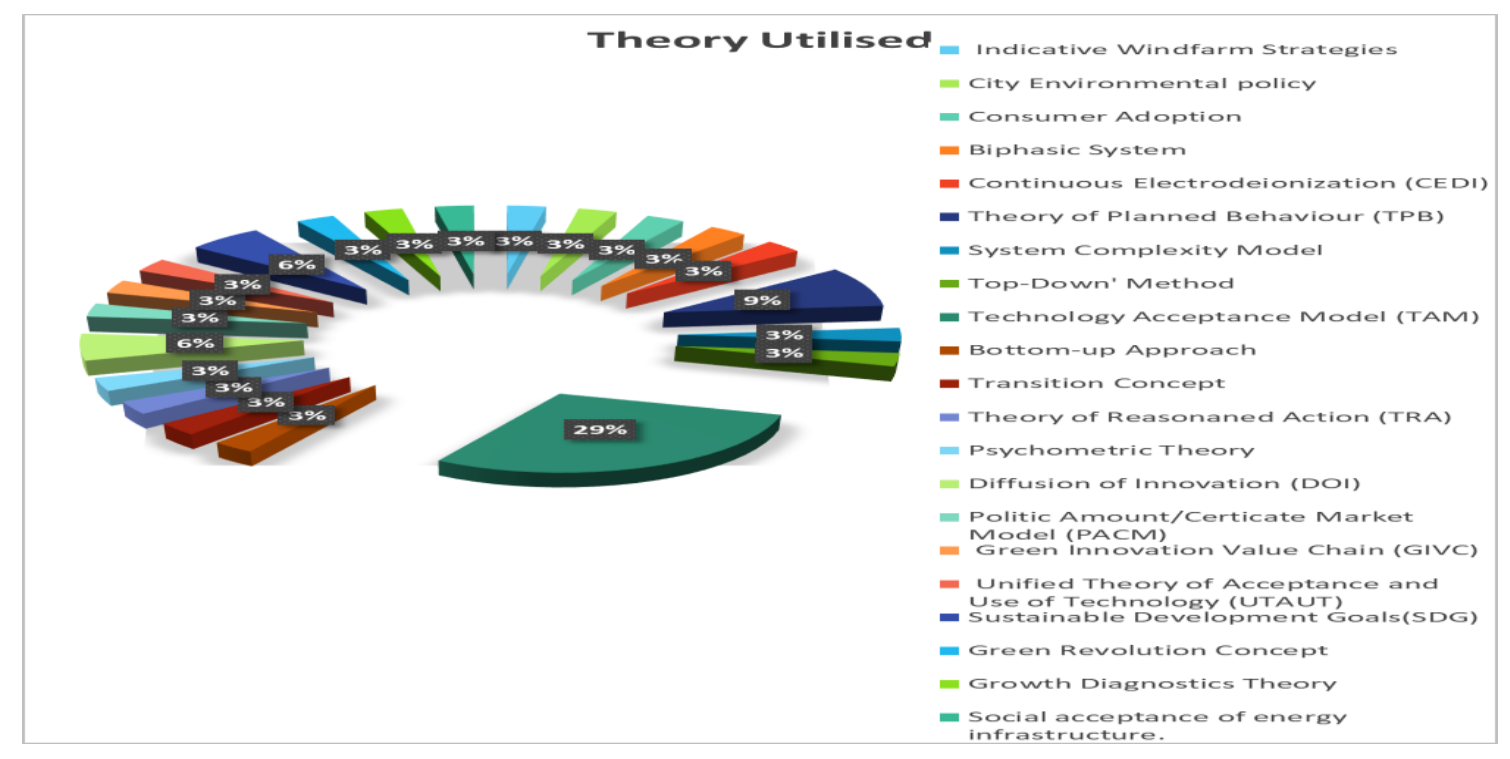

Fig.4: Theory utilized

\section{v. Subject Area Base}

Based on the figure above, it shows a subject area that had been selected for this study. All this data was gain from the Scopus database. As in Scopus, there are many more subject areas such as Energy, Engineering, Psychology and so on. But for these 46 selected articles, researcher only included three main categories of subject area that suitable for green technology field which is Social Science, Environmental Science and lastly Business, Management and Accounting. The highest subject area in green technology acceptance for this paper is environmental science which is around 27 papers are from that background. Next, the second highest of subject area is social science which is around 12 papers published on this area. Lastly is the Business, Management and Accounting area which is around 7 articles are published in this subject area. All data were gain after the selection process while screening the data. 


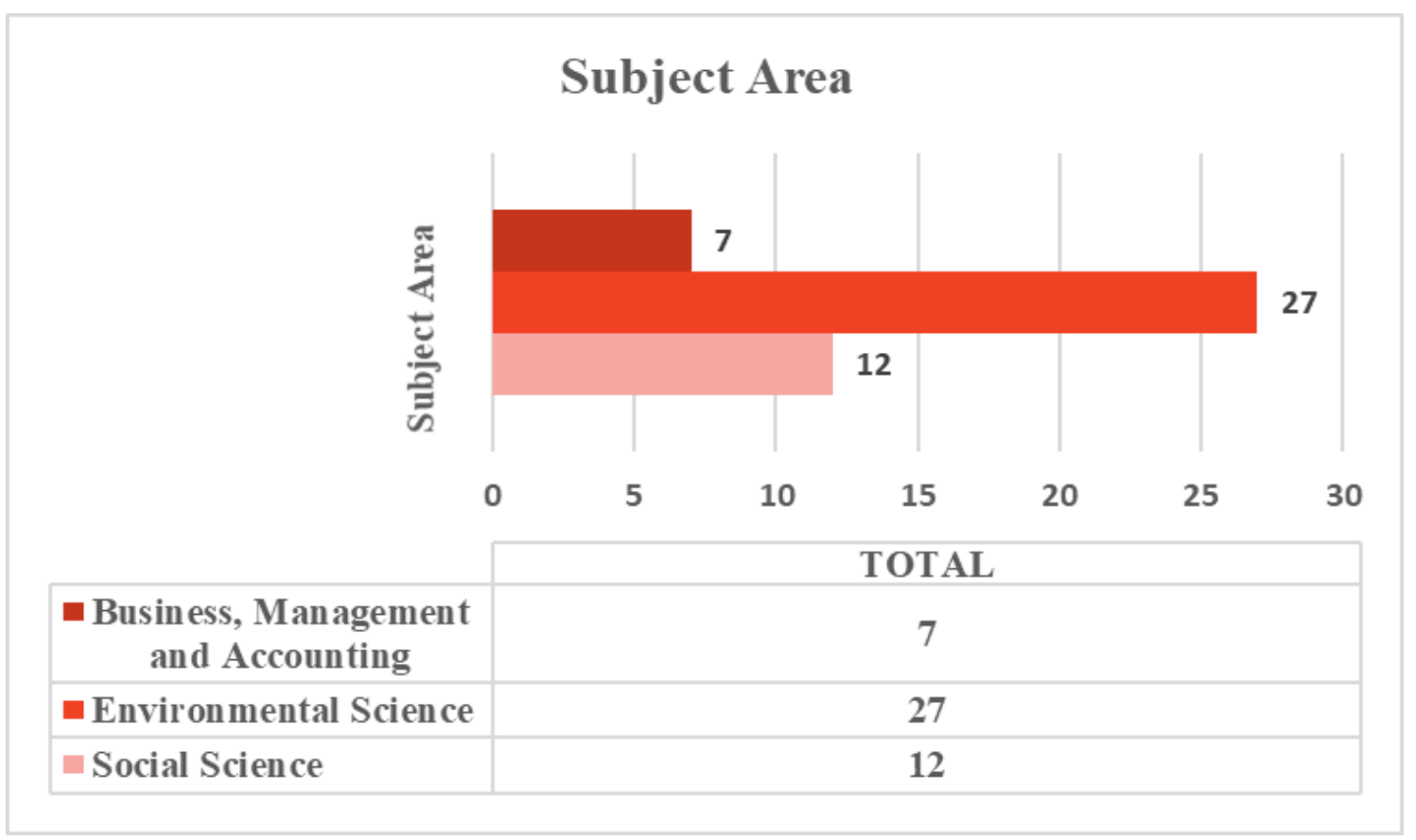

Fig.5: subject area

\section{Classification}

Information and detailed discussions are performed in this section after the classified categories were completed. Based on the 46 articles that had been throughout the process, researcher come out with method classification which is in three types of methodology:

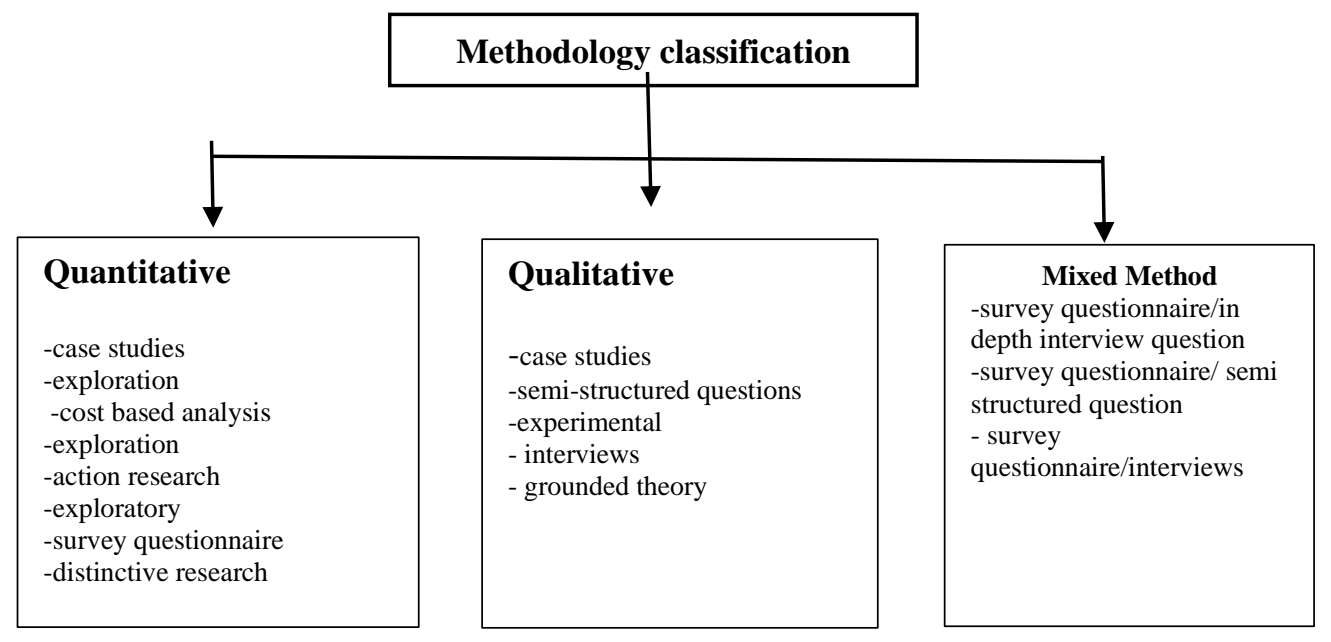

Fig.6: Methodology classification

\subsection{Quantitative Method}

In this review paper, researcher found out there are around 26 papers that used quantitative in their research method. A methodology offers the theory, values and assumptions of a piece of research which influence the justification for the analysis, along with standards used for interpretation data and find out conclusion of the results. Quantitative analysis is known to be a deductive research methodology. Usually researcher will use this type of data analysis in order to find out the relationship between the independent variables and dependent variables. This method is characterized by a theory that researcher proposes by illustrated in a particular hypothesis then tested; conclusions on this theory can be drawn after a set of observations and data analysis 
(Almalki et al., 2016). As larger samples are typically considered by quantitative method, data reduction processes are very useful in the interpretation of data as well as in getting the result for study(Fischer et al., 2014). Based on the review that had been done, there are around 26 research paper using quantitative methodology but with different type of data collection such as survey questionnaire, case study, action research, exploratory and even cost based analysis.

Some of the collection are discussing about the quantitative analysis on modelling electric vehicle usage intentions. According to this research, more precisely, 1000 private drivers in Malaysia obtained an observational analysis using a survey questionnaire. On the justification of a literature review and a multiple regression model, an electric vehicle framework was suggested. The findings have shown that the adoption of electric vehicles in Malaysia is strongly linked to social factors, performance characteristics, demographics, concern in environmental, readiness towards infrastructure and policy engagement (Sang \& Bekhet, 2015). Besides that, several researchers studied the possible effects of Autonomous Electric Vehicles (AEVs), although others concentrated on public opinion in relation to AEVs. The main reason the researcher chooses quantitative analysis because to test the hypothesis based on the two different theory which is Technology Acceptance Model (TAM) and also Theory of Planned Behaviours (TPB). The data were gathered and analysed using a systemic model from an online survey in China and found out that factors such as green perceived usefulness, ease of use and environmental concern contribute favourably to people's decisions to use AEVs (J. Wu et al., 2019). In the form of quantitative data analysis, substantially boosts reaction rates and analyses of obtained the results (Ohueri \& Enegbuma, 2019).

In addition, based on this review paper, the quantitative data analysis is being used much more because based on the nature of the study. Some study need an interview when the respondents or scope of the study just small meanwhile when the study need more respondent's researcher will go on with the questionnaire survey. Based on one study in the selected paper, the main objective of the study is to explain the existence and experience of buying intentions for electric vehicles. So, by adapting the TAM theory, the researcher come out with 21 items on questionnaire survey and around 305 electric motorcycles users had been distributed the questionnaire to get the information regarding to this study(J. H. Wu et al., 2015). As this study aim is to find out the intention of buying, it's very suitable to go through by the quantitative analysis. The result of this study reveals an empirical evidence of relationship between the value, perceived usefulness, image, risk towards purchase intention. In order to highlight the measures, general trends and market requirements, the researcher used the quantitative approach for evaluating data collection outcomes (Khan et al., 2020).

On other hand, one of the paper that had been selected were discussing about the green agriculture in term of Internet of Things (IoT). A network of interlinked computing systems, mechanical and electronic machines, objects or humans, with the ability to transmit data across the network with unique identification systems (UIDs) without the need for contact between human beings or humans and computers. This report focuses upon elements of valuebased acceptance by applying the Technology Acceptance Models (TAM) and creates a distinctive research template. The researchers also extend the services-dominant principle towards this research by connecting specific elements of perceived interest to IoT technology. The research focuses on how trust affects value and risk perceived what is the impact on IoT adoption. In this report, the researchers choose the quantitative method by run the hypotheses by based on the framework. The sample of this study is involving 492 farmers from Lowa, USA. The main advantages by using this quantitative research is as long as researchers are able to support that respondents are fit into their study population categories; personal information is not needed. The anonymity of quantitative research makes it effective for data collection since people tend to communicate honestly for their point of view when there are guarantees that their responses does not return to affect them

Moreover, this paper also to find out the level of acceptance towards green technology around the world. Mostly all of the paper are using the quantitative analysis method in order to produce the framework from theory that had been adapted such as TAM, TPB and also UTAUT. Overall, all of this theory are discussing on the behaviour, intention, perceptions, adoption or even acceptance of users towards the technology. By having the quantitative data analysis method, the researcher later on will come out with the hypothesis that will be run out through the data analysis in order to find out the relationship between the variables. In the same time, using this quantitative analysis data also bring more advantages. Researchers gather information in real-time situations for the quantitative method, meaning that scientific and mathematical analysis can take place nearly instantly (Fitri et al., 
2017). Questionnaires, surveys and interviews offer instant results that gained from the data-cantered approach. The lower the uncertainties in the development of these tools, the easier to promote the connection towards meaningful result. In order to focus on a particular aspect, researchers could have used the quantitative method to analyse the general population. This approach is often useful where a variety of data sources within a particular demographic are particularly desired. It is a mechanism that helps one to consider the explanations behind their choices, behaviour or actions from a social point of view.

\subsection{Qualitative Method}

In this review paper, researcher found out there are around 17 papers that used qualitative in their research methodology. Qualitative method also one of the method that usually had been used in collecting data for research. Qualitative is primarily used as a data gathering technique (such as interview) or data analyse method such as categorizing data that produces or uses non-numerical data (Saunders et al., 2009). Therefore, qualitative method may focus on the data besides the words, like photos and video clips. In a short word, qualitative method is more on capturing people's opinions and emotions freely without having any limitation. There are few advantage by using this research methodology such as qualitative research approaches are not limited compared to quantitative. If the answers are not compatible with the expectation of the researcher, qualitative data is evenly useful to add context and will be able to explain something that cannot be revealed by numbers alone. Based on the review that had been done, there are around 17 research paper using qualitative methodology but with different type of data collection such as case studies, semi-structured question, experimental, interview and grounded theory.

Some of research are discussing on marketing strategies and market prospects for environmentally friendly consumer products. The paper was published on 1996, its showed that as early as in 1996 people already have the environmental friendly behaviours towards the nature. This paper reflects on the role manufacturers were playing and updates on the results of an inquiry into marketing strategies of companies and their awareness of potential advantages for green products in the United Kingdom (Wong et al., 1996). The researcher was using the quantitative data analysis via interviews with senior executives, using a semi-structured questionnaire. A semistructured tool has been used to expand the data generated so that useful qualitative information could be obtained. The researchers were able to examine for the bias and misinterpretation in the responses from personal interviews. Its shows that from earlies in 1990s, people already aware towards the green technology field as they know that green products will bring more environmental friendly to the world.

Other than that, one of the study in the review paper was exploring on green public procurement. Days by days many new green technology areas area exist in this world. There are an assumed that green public procurement can help preserve the environment and enhance green technology. The objective of the paper is to review and contrast the way in which two Swedish areas encourage the implementation of renewable fuels in their public transport service through public procurement (Aldenius \& Khan, 2017). The approach that this study used is comparative case studies based on the interview and record analysis. There were two major reasons why researcher choose to perform a qualitative analysis. Firstly, because the implementation of green procurement contracts in the Swedish bus industries was not previously researched, so an exploratory analysis was deemed useful to establish the major factors that affect its uses. Secondly, some previous research on this topic have been planned in a quantitative way. The purpose of using the qualitative studies is to gain further data and information regarding to the topic as open ended question usually had been used while interview.

In addition, as this review paper had been selected in some areas such as environmental science it's also including the green physics areas. One of the paper are reported based on the green chemistry which is discuss on the continuous electrodeionisation of ultrapure water. Electrodeionisation (EDI) and deionisation of mixed beds (MBDI) usually take the same stance as those used in the technological plan for the consumption of ultra-pure water to support (situation) reverse osmosis (RO) encompass purification (Fedorenko, 2004). A descriptive study of EDI and MBDI 's principal disparities allows this method in water condition technology to be used more properly. The researcher used experimental method as this process are used by the process of continuous electrodeionization (CEDI). This experimental study is a form of research projects that use modification and repeatable testing to recognize casual operations usually used within fields of science such as electrics, sociology, mathematics, psychology, medication, physics, biology and chemistry. One or even more independent variable 
must be manipulated to evaluate the influence on the dependent variable. By used this type of method, the researcher will be able to discovery of the association between cause and effect is simple because this method of study aims at factors such that an association between cause and effect can accurately be defined (Miller, 2019). Qualitative method is one of the best option for the researcher when they want to have a small number of the population or sample size. Usually, the qualitative researchers obtained more important data on a concept, knowing that the main limitation is that the findings are not widely available to a population as just few respondents take part in research which is so detail -oriented (Jackson et al., 2007). This understanding of subjectivity often contributes to improved reliability measures such as participation supervision. That by doing so the researcher observes the study of the experiences of others limits the experience of the researcher, and this has impacts on social science collection of the results obtained. Each of the method has it own advantages and disadvantage, the best ways to aim for the best methodology is by knowing their own research nature.

\subsection{Mixed Method}

In this review paper, researcher has sorted out that around 3 papers out of 47 papers that had been selected use the mixed method analysis. Some types of the mixed method that been found in this research is combination of survey questionnaire with in depth interview questions, survey questionnaire with semi structured questions and lastly survey questionnaire with interviews. Mixed method can be describing as combination of both research methods which is quantitative and qualitative where the research from basic, simultaneous pattern towards more complex and sequential forms (Saunders et al., 2016). In the same time, mixed methodology study integrates the use of multi methods research which is quantitative and qualitative data analysis techniques and procedures. Using mixed method will give some advantage to the researcher as, researchers may explore a wider and deeper variety of research topics as the researcher is not limited to the concepts of a specific research method. Moreover, researchers may use the power of a research method to combat the shortcomings of a particular method or to resolve them.

One of the study in this review paper are using mixed method on the public acceptance of marine renewable energy in Malaysia. This study is using questionnaire survey and interviews. First of all, the researcher was distributed around 250 questionnaires to the targeted respondents. After that, the researcher went through the individual interview towards the expert in the area of environmental issues. The interview had been done in order to collect the qualitative data by having an open ended question and to understand the opinion on the field and in the ned of process researcher will be able to integrate the quantitative data with the qualitative data analysis (Lim \& Lam, 2014). As the questionnaire is very limited answer as the respondent are being able to choose answer that stated in the survey meanwhile while went through the interview, open question can be asked and more accurate answer will be gained. By using this mixed method, researcher will be able to make a good conclusion with strong evidence through integration and alignment of observations.

\section{Conclusion}

After done the technique of PRISMA Model, the researcher found out there are around 47 papers that suitable for this study. The green technology fields are started many decades ago and until todays it's still moving towards the development. Many new areas of green technology are coming such as green procurement, green purchasing, green building and many more. Some of the papers are clearly stated the full abstract of their research so it will be more easily for researcher to find information that will be useful for them. Mostly, the papers are having a good abstract which help to gain information just by read it. Researcher also find out that mostly when others researcher discusses on this green technology acceptance topic they would like to reflect back on the existing theories. Theories such as TAM, TPB and UTAUT are the favourites among the researcher as all of this theories are discussing on the level, behaviour, perception, adoption or even acceptance towards a technology. Some of the limitation in this study is, the researcher is not select specific time line and may be for the future research it can be more specific on the time base so researcher will be able to see the line or pattern of the acceptance of green technology around the worlds. 


\section{References}

Abu-dalbouh, H. M. (2013). A Questionnaire Approach Based on the Technology Acceptance Model for Mobile Tracking on Patient Progress Applications. 9(6), 763-770. https://doi.org/10.3844/jcssp.2013.763.770

Aldenius, M., \& Khan, J. (2017). Strategic use of green public procurement in the bus sector: Challenges and opportunities. Journal of Cleaner Production, 164, 250-257. https://doi.org/10.1016/j.jclepro.2017.06.196

Ali, N. N., Murad, M. A., \& Jabar, J. (2019). Factors That Affect the Green Technology Awareness in Melaka. 3(2), 75-80.

Almalki, S., Centre, E. L., Arabia, S., \& Centre, E. L. (2016). Integrating Quantitative and Qualitative Data in Mixed Methods Research - Challenges and Benefits. 5(3), 288-296. https://doi.org/10.5539/jel.v5n3p288

Fedorenko, V. I. (2004). Ultrapure water production by continuous electrodeionization method: Technology and economy. Pharmaceutical Chemistry Journal, 38(1), 35-40. https://doi.org/10.1023/B:PHAC.0000027643.24808.81

Fischer, H. E., Boone, W. J., Fischer, H. E., \& Boone, W. J. (2014). Quantitative Research Designs and Approaches Quantitative Research Designs and Approaches University of Duisburg-Essen, Essen, Germany Knut Neumann Leibniz-Institute for Science and Mathematics Education (IPN ), Kiel, Germany. October 2015.

Fitri, H., Latip, M., \& Syahrom, A. (2017). A Questionnaire-based Approach on Technology Acceptance Model for Sains Humanika A Questionnaire-based Approach on Technology Acceptance Model for Integrated Multiple Ankle Technology Device on Patient Psychology. July. https://doi.org/10.11113/sh.v9n3-2.1267

Iravani, A., akbari, M. H., \& Zohoori, M. (2017). Advantages and Disadvantages of Green Technology; Goals, Challenges and Strengths. International Journal of Science and Engineering Applications, 6(9), 272-284. https://doi.org/10.7753/IJSEA0609.1005

Jackson, R. L., Drummond, D. K., \& Camara, S. (2007). What is qualitative research? Qualitative Research Reports in Communication, 8(1), 21-28. https://doi.org/10.1080/17459430701617879

Khan, N., \& Qureshi, M. I. (2020). A Systematic Literature Review on Online Medical Services in Malaysia. International Journal of Online and Biomedical Engineering (IJOE), 16(06), 107. https://doi.org/10.3991/ijoe.v16i06.13573

Khan, N., Qureshi, M. I., Mustapha, I., Irum, S., \& Arshad, R. N. (2020). A systematic literature review paper on online medical mobile applications in Malaysia. International Journal of Online and Biomedical Engineering, 16(1), 63-82. https://doi.org/10.3991/ijoe.v16i01.12263

Krishnan, G., Sandhu, S. C., Prothi, A., Singru, R., \& Dijk, N. van. (2014). Gr EEE n Actions Master Plan on ASEAN Connectivity Implementation ( RETA 8040 ). Melaka Green City Action Plan 2014, April, 1-69.

Labex Korea. (2013). Green Technology: The 10 leading countries. https://labexkorea.files.wordpress.com/2010/08/top10_verde.pdf

Lal, K. (2018). “ Green Globalization as Green Technology and Renewable Energy. ” 8(9), 41-53. https://doi.org/10.9790/9622-0809024153

Lim, X. Le, \& Lam, W. H. (2014). Public acceptance of marine renewable energy in Malaysia. Energy Policy, 65, 16-26. https://doi.org/10.1016/j.enpol.2013.09.053

Lim Wei PIng. (2012). A STUDY ON FACTORS INFLUENCING GREEN INFORMATION TECHNOLOGY ADOPTION AMONG MANUFACTURING FIRMS IN PENANG, MALAYSIA Research report submitted in partial fulfillment of the requirements for the degree of Master of Business Administration UNIVERSITI SAINS M.

Markom, R., \& Hassan, N. (2014). The Harmonization of Environmental Sustainability, Green Energy and Green Technology from the Islamic Perspectives. Xxx, 1-7.

McCranie, K. D., Faulkner, M., French, D., Daddis, G. A., Gow, J., \& Long, A. (2011). Awareness of Green Technology in Chinese New Village. Journal of Strategic Studies, 34(2), 281-293. https://doi.org/10.1080/01402390.2011.569130

Miller, B. (2019, December 16). 8 Main Advantages and Disadvantages of Experimental Research. Retrieved July 07, 2020, from https://greengarageblog.org/8-main-advantages-and-disadvantages-of-experimental-research

Odigure, J. O. (2016). Green Technology: A veritable Tool for Achieving Technological Transformation and Diversification of the Nation's Economy Presented@7 Biennial National Engineering Conference The Federal Polytechnic, Bida, Niger State, Nigeria 20 th September, 20. October.

Ohueri, C. C., \& Enegbuma, W. I. (2019). MyCREST embedded framework for enhancing the adoption of green office building development in Sarawak framework. 2018. https://doi.org/10.1108/BEPAM-10-2018-0127

Qureshi, M. I., Khan, N., Hassan Gillani, S. M. A., \& Raza, H. (2020). A Systematic Review of Past Decade of Mobile Learning: What we Learned and Where to Go. International Journal of Interactive Mobile Technologies (IJIM), 14(06), 67. https://doi.org/10.3991/ijim.v14i06.13479

Sang, Y. N., \& Bekhet, H. A. (2015). Modelling electric vehicle usage intentions: An empirical study in Malaysia. Journal of Cleaner Production, 92, 75-83. https://doi.org/10.1016/j.jclepro.2014.12.045

Saunders, M., Lewis, P., \& Thornhill, A. (2009). Research Methods for Business Students (Fifth Edition) (Vol. 5, Issue 1). https://doi.org/10.1080/09523367.2012.743996

Saunders, M., Lewis, P., \& Thornhill, A. (2016). Research Methods For Business Students (Seventh Edition).

Science, E. (2019, March 18). History of Green Technology. Retrieved July 02, 2020, from https://www.ukessays.com/essays/environmental-sciences/history-of-green-technology-environmental-sciences- 
essay.php

Show, K. (2010). Green technology.

Tahir, N. H., Rajiani, I., \& Muslan, N. (2015). GREEN TECHNOLOGY READINESS IN MALAYSIA : SUSTAINABILITY FOR GREEN TECHNOLOGY READINESS IN MALAYSIA : SUSTAINABILITY FOR BUSINESS DEVELOPMENT Kamarudin Abu Bakar*, Mohd Fazli Mohd Sam ,. August.

Teo, T., Koh, N. K., \& Lee, C. (2011). Teachers 'Intention to Teach Financial Literacy in Singapore : A Path Analysis of an Extended Theory of Planned Behaviour ( TPB ). 2, 410-419.

Wong, V., Turner, W., \& Stoneman, P. (1996). Marketing strategies and market prospects for environmentally-friendly consumer products. British Journal of Management, 7(3), 263-281. https://doi.org/10.1111/j.1467-

8551.1996.tb00119.x

Wu, J. H., Wu, C. W., Lee, C. T., \& Lee, H. J. (2015). Green purchase intentions: An exploratory study of the Taiwanese electric motorcycle market. Journal of Business Research, 68(4), 829-833. https://doi.org/10.1016/j.jbusres.2014.11.036

Wu, J., Liao, H., Wang, J. W., \& Chen, T. (2019). The role of environmental concern in the public acceptance of autonomous electric vehicles: A survey from China. Transportation Research Part F: Traffic Psychology and Behaviour, 60, 37-46. https://doi.org/10.1016/j.trf.2018.09.029 